\title{
Los recursos hídricos en las regiones indígenas de México
}

\author{
Water Resources in Indigenous Regions of Mexico
}

\author{
Yanga Villagómez Velázquez* (i) https://orcid.org/0000-0003-0776-5818 \\ Emanuel Gómez Martínez ** iD https://orcid.org/0000-0002-9527-7672
}

\section{Resumen}

El objetivo de este artículo es contribuir con información al debate sobre el diseño de una política hídrica con visión intercultural en México. Se analiza la gestión de los recursos hídricos en los territorios indígenas de México con un enfoque centrado en el derecho humano al agua. La metodología consiste en combinar dos bases de datos relevantes para entender la disponibilidad del recurso en esas regiones y localizar las concentraciones de población indígena. Entre las limitaciones de la investigación está que la interpretación etnográfica se basó sólo en publicaciones antropológicas, a pesar de que es necesaria la información de primera mano - un estudio de caso, por ejemplo - para comprender la relación conflictiva entre la gestión del agua y los pueblos indígenas. La originalidad del documento es que sintetiza la información hidrológica y antropológica en un contexto de derechos colectivos. En las conclusiones se propone que las estrategias para el manejo del agua tomen en cuenta la organización de estas comunidades para que puedan intervenir en la toma de decisiones para los mecanismos que se están creando en la Ley de Aguas Nacionales.

Palabras clave: políticas públicas; agua; pueblos indígenas; conflictos hídricos; gestión del agua.

\section{Abstract}

The purpose of this article is to add information to the water policies design's debate with intercultural view in Mexico. It analyses water resources management in the lands inhabited by indigenous peoples, focused on human right to water. Methodology consists on combining two relevant databases to understand water accessibility in those lands and to locate the concentration of indigenous population. Among its limitations is that the basis of ethnographic interpretation were anthropological publications even though it is necessary firsthand information to understand the conflictive relationship between water management and indigenous people; consequently it should have been better to select case studies. The originality of this document is that synthetizes hydrological and anthropological information within a context of collective rights. Conclusions lead to propose that water management strategies should take into account these communities organization in such a way they can participate in decision-making related to the procedures that actually are created in the $\mathrm{Na}-$ tional Water Law.

Keywords: public policies; water; indigenous peoples; water conflicts; water management.

Cómo citar: Villagómez Velázquez, Y., y Gómez Martínez, E. (2020). Los recursos hídricos en las regiones indígenas de México. región y sociedad, 32, el 288. doi: I0.22I 98/rys2020/32/I 288

* El Colegio de Michoacán, Centro de Estudios Rurales. Martínez de Navarrete Núm. 505, Col. Las Fuentes, C. P. 59699, Zamora, Michoacán, México. Correo electrónico: yangavillagomez@gmail.com

** Autor para correspondencia. Universidad Autónoma Chapingo, Dirección de Centros Regionales, sede Chiapas. Diego de Mazariegos Núm. 85, La Merced, C. P. 29240, San Cristóbal de Las Casas, Chiapas, México. Correo electrónico: pinotzin@gmail.com

Recibido: 14 de enero de 2020

Aceptado: 4 de junio de 2020

Liberado: 30 de julio de 2020

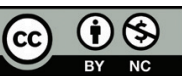

Esta obra está protegida bajo una Licencia

Creative Commons Atribución-No Comercial 4.0 Internacional. 


\section{Introducción}

Una idea central de este trabajo se relaciona con la localización de los territorios indígenas y de sus poblaciones respecto a las cuencas hidrológicas en México. Si se parte del dato de que la mayoría de los territorios indígenas se encuentran en las cabeceras de cuenca, es urgente actualizar los instrumentos oficiales de gestión del agua para que se reconozcan los mecanismos utilizados por los pueblos indígenas para mantener en buen estado las zonas de captación. Para eso se requiere una gestión intercultural de las políticas hídricas; es decir, hay que tomar en cuenta los criterios institucionales y los que ya existen en las comunidades para una mayor eficiencia en el uso del recurso. La sobreexplotación de los recursos hídricos, las variaciones climáticas, la construcción de trasvases, la rivalidad de usuarios en su competencia por el acceso al agua, el sobreconcesionamiento o su uso ineficiente pueden provocar periodos de escasez. Es importante fortalecer y llevar a cabo los acuerdos con las autoridades municipales para asegurar el abasto eficiente de agua a los habitantes que residen en las localidades o en las ciudades ubicadas fuera de la zona de influencia de los territorios indígenas pero que dependen del recurso que nace en esas regiones.

Cerca de 63\% del territorio nacional tiene clima semidesértico. En 30\% de su superficie, en el norte sobre todo, se genera $4 \%$ del escurrimiento, mientras que en el sur-sureste y zonas costeras, que representan $20 \%$, se genera $50 \%$ de éste. Del escurrimiento medio anual, $19 \%$ se extiende en poco más de la mitad de la superficie del país, que corresponde a la zona del norte y del altiplano central, donde se concentran dos tercios de la población nacional, $70 \%$ de la actividad industrial, $40 \%$ de las tierras de temporal y se genera $83 \%$ del producto interno bruto (PIB) nacional (Comisión Nacional del Agua [CONAGUA], 2018, p. 24).

En síntesis, una de las grandes contradicciones de la ocupación espacial y de la distribución de la población en el territorio mexicano es que la mayor parte de la población se encuentra en las regiones del norte, donde los recursos hídricos son escasos; en contraste, el sur-sureste tiene poca densidad demográfica, altos índices de pobreza y abundantes recursos naturales: agua, gas, petróleo, minerales, zonas turísticas y parques generadores de energía eólica.

Por otro lado, $50 \%$ del agua que se consume en el país se extrae de 104 acuíferos, de un total de 653 , lo que permite deducir que el resto se obtiene de las aguas superficiales, sobre todo de zonas áridas y semiáridas (CONAGUA, 2005).

En México, la CONAGUA ha definido 757 cuencas hidrológicas (2018, p. 31) y entre ellas algunas de las exorreicas más importantes corresponden a los grandes ríos nacionales, como el Lerma, el Santiago, el Balsas, el Bravo, el Pánuco, el Papaloapan, el Coatzacoalcos, el Grijalva, el Usumacinta, el Mayo y el Yaqui. Para los objetivos de formulación y de ejecución de las políticas públicas relacionadas con los recursos hídricos del país, así como para los propósitos de propiciar una participación en la gestión integral del recurso, el interés se concentra en tres niveles de cuenca: las macrocuencas, que corresponden a grandes sistemas hidrológicos, las subcuencas o cuencas de segundo orden y un tercer nivel que puede denominarse microcuencas. 
Pero si se analiza en detalle, se detecta que existe un conflicto estructural: de manera institucional, el agua se gestiona por cuencas y macrocuencas, con criterios hidrológicos; en cambio, los pueblos indígenas lo hacen mediante asambleas de diferente nivel (ejidal-comunal y municipal) y, en algunos casos, constituyen alianzas entre varios núcleos agrarios e incluso entre varios municipios. Aunque ambas formas de organización son administrativas, hay diferencias. En las comunidades indígenas los usuarios se organizan basándose en su territorio, en sus sistemas de propiedad de la tierra, lo que se expresa en diferentes modos de apropiación y aprovechamiento y conservación de los ecosistemas. No se limitan a la demarcación geopolítico-administrativa de la cuenca (Murillo-Licea, 2019). Además, su visión de la naturaleza -que se sustenta en prácticas colectivas- es holística, integral y no fragmentada, e incluye el componente cultural, que no se puede omitir debido a su importancia en las comunidades indígenas y que involucra la aplicación de normas que pertenecen al ámbito del derecho consuetudinario, el uso y despliegue de tecnologías vernáculas, formas específicas de gobierno y de acuerdos tomados por la colectividad y que se transmiten de manera oral. Para analizar este conflicto, en el siguiente apartado se aborda la relación de los pueblos indígenas con los recursos hídricos desde una perspectiva cultural.

\section{El agua en las culturas de los pueblos indígenas de México}

Diversas investigaciones han demostrado que los pueblos indígenas, en su conjunto, usan entre 5000 y 7000 especies de plantas, además de que su sistema alimentario comprende entre 1000 y 1500 especies (Caballero, 1985, citado en Boege, 2008, p. 21). Lo anterior es consecuencia del manejo que tienen de sus territorios y de la biodiversidad que existe en ellos.

Retomando el debate antropológico sobre la construcción social de la región a partir de las territorialidades en contraposición con la estructura institucional basada en regiones administrativas, se define aquí el territorio indígena "como un espacio apropiado y valorizado simbólica e instrumentalmente por los pueblos indígenas" (Toledo, 2010, p. 175). En contraste, se define la región administrativa como unidad territorial que constituye subconjuntos dentro del ámbito de un Estado-nación y en la que sus partes interactúan más entre sí que las de sistemas externos (Giménez, 1994).

A lo largo de la historia de México y desde la segunda década del siglo XX, estas dos formas distintas de organizar la gestión de los recursos hídricos del país han convivido a escala regional con conflictos y tropiezos, reflejando las características específicas de la formación social de México. Es decir, se tiene la diversidad de los pueblos indígenas con sus propias lenguas, organización social y cultura, en contacto con los ecosistemas y los niveles de biodiversidad importantes (Toledo et al., 2001). Estos pueblos tienen un reservorio de conocimientos ecológicos y tecnologías vernáculas que se aplican al manejo de los recursos naturales como parte de su patrimonio natural y cultural, que es producto de una cultura hidráulica que se remonta a la aplicación y al uso 
de una tecnología ancestral, tal y como lo han demostrado las investigaciones realizadas sobre el tema (Rojas-Rabiela, Martínez-Ruiz y Murillo-Licea, 2009; Sandre-Osorio y Murillo, 2008).

La disponibilidad de agua en las regiones geográficas en las que se asentaron los ancestros de los actuales pueblos indígenas fue determinante para la organización social, territorial y económica. Para los arqueólogos y antropólogos, lo que hoy conocemos como norte de México, se corresponde con lo que se ha denominado Aridoamérica, lo que se conoce actualmente como desiertos de Sonora y Arizona, se denomina Oasisamérica, y el sur-sureste de México, se denomina Mesoamérica (López-Austin y López-Luján, 1996; Navarrete, 2004, pp. 38-39; Wolf, 1967).

Además, en una amplia gama de trabajos se ha dado cuenta del uso de ciertas formas jurídicas y de gobierno propias que se diferencian de las formas de gestión del agua usadas por las agencias encargadas de administrarla en el país. Esto plantea retos en cuanto a las decisiones que se toman sobre el acceso equitativo y regulado de los diferentes sectores de usuarios que hay en la sociedad, por lo que se tienen que atender las asimetrías que hay en el funcionamiento de la administración pública del agua, considerando, sobre todo, que es necesario asegurar el acceso oportuno al agua de buena calidad para todos. Hay que tener en cuenta que las culturas indígenas de México mantienen activa la "visión estructurada en la cual los antiguos mesoamericanos combinaban de manera coherente sus nociones sobre el medio ambiente en el que vivían y sobre el cosmos en el que situaban la vida del hombre" (Broda, 1991, p. 462).

Como consecuencia de las nuevas condiciones que se presentan para el acceso a recursos como el agua -que es objeto de procesos de rivalidad por parte de agentes económicos, como las empresas mineras- y las evidentes consecuencias de ecocidio ya abordadas en investigaciones, como por ejemplo, el caso de los wixaritari o huicholes en defensa de Wirikuta (Liffman, 2017). Las cosmovisiones, rituales y ceremonias vinculadas al territorio siguen teniendo un papel destacado, ya que son espacios de uso cotidiano en un contexto sagrado y ritualizado. En esa medida, las pilas, los manantiales, algunas cuevas, los árboles y los cerros se siguen considerando lugares sagrados, por lo que en ellos se practican ceremonias religiosas y rituales que dan continuidad y vigencia a la herencia del patrimonio simbólico.

Desde esta perspectiva, el agua es más que un recurso hídrico de carácter económico: forma parte de una visión especial en relación con la naturaleza y con las formas de apropiación que se dan a través del conocimiento del ciclo hídrico natural, de las prácticas sociales de aprovechamiento de este recurso de manera sustentable, de la tecnología que se aplica para nutrir y manejar los suelos de forma adecuada y de la concepción del funcionamiento de los ecosistemas y sus especies de flora y fauna. El agua es, en este sentido, un componente asociado de manera inevitable con lo vivo y, por lo mismo, con las especies que integran los ecosistemas que pertenecen a los territorios de los pueblos indígenas.

El culto al agua y los rituales agrícolas han trascendido el tiempo y los periodos históricos; la repetición anual permite la continuidad y la reinterpretación 
del vínculo con el pasado prehispánico. En la actualidad, exhiben una serie de trasformaciones, adaptaciones y cambios que responden a sus contextos social, cultural y económico.

El agua es un recurso que se encuentra materialmente en el mar, las lagunas, los manglares, los ríos, los riachuelos de las montañas, las zonas de pesca y caza, o como una ruta para el intercambio comercial. De manera simbólica, aparece en la narrativa oral sobre el diluvio y el fin del mundo, en infinidad de leyendas que mezclan creencias de origen prehispánico con la experiencia de la colonización y de la modernización (González-Pagés, 2006). En los ríos y en los lagos viven sirenas, peces mágicos, chaneques y dioses protectores, en cuya dualidad la parte femenina se relaciona con la mujer, la luna y la fertilidad. Hay también diosas que aparecen como símbolo central en la cosmovisión de los pueblos indígenas (Félix-Báez, 1992).

En el campo de la salud y de la medicina tradicional, el agua es un elemento dual y dicotómico, ya que se le atribuyen cualidades positivas y negativas, ya sea como recurso terapéutico o como contaminante y destructor cuando se presenta en forma de inundaciones o causa daño directo a las personas mediante el ahogamiento y la enfermedad.

Otra función del agua es prevenir algún mal, como el agua bendita y la que se usa para curación. El agua se "activa" por medio de rituales o cuando se pone en contacto con otros elementos, como la tierra, el humo de incienso y las plantas. Las aguas termales también son un medio natural curativo. Otras fuentes de sanación y por lo tanto de devoción son los manantiales, fuentes consideradas milagrosas y cuya potenciación se cree es obra de los dioses.

En síntesis y retomando a Martínez-Ruiz y Murillo-Licea (2016), para los pueblos indígenas de México el agua es parte de una cosmovisión que delimita un territorio ancestral para apropiárselo a partir de la oralidad y su sistema consuetudinario de gobernanza, también conocido como los usos, costumbres, tradiciones, rituales, acuerdos, normas y prácticas de manejo de los recursos naturales. Estos modos específicos de aprovechamiento son reconocidos en el derecho internacional como parte del derecho a la propiedad (Comisión Interamericana de Derechos Humanos [CIDH], 2010; Forero-Mantilla, 2010), o más atinadamente, como patrimonio cultural, que es simultáneamente un patrimonio material e inmaterial (López-Ledesma, 2018). Sin embargo, las políticas hídricas se diseñan y operan con otros criterios, como se verá en el siguiente apartado.

\section{Políticas públicas y gestión del agua}

En términos de distribución, $82 \%$ del volumen de almacenamiento de agua en México se encuentra a no más de 500 metros sobre el nivel del mar, mientras que $76 \%$ de la población vive en localidades que se encuentran por encima de esa altitud. Esta diferencia conduce a la necesidad de encontrar soluciones técnicas para asegurar el abasto en concentraciones rurales y urbanas. El país se puede dividir en dos grandes zonas: la norte, centro y noroeste, donde se 
concentra $77 \%$ de la población y se genera $78 \%$ del PIB; en ella se localiza $31 \%$ del agua renovable, y la zona sur-sureste, donde se localiza $23 \%$ de la población, se genera $22 \%$ del PIB y donde hay $69 \%$ del agua renovable (CONAGUA, 2011, p. 18).

Las cabezas de cuenca se caracterizan por ser zonas altas, con distintos tipos de bosques que concentran la captación, la retención y el almacenamiento de agua de lluvia. Son la base para delimitar las cuencas del país y, al mismo tiempo, es donde la presencia de población indígena es más significativa, sobre todo en el sur-sureste de país. Las sierras y los valles de estos lugares dan origen a las 757 cuencas hidrológicas definidas por la CONAGUA, junto con sus disponibilidades, el 7 de julio de 2016 conforme a la norma NOM-011-CONAGUA-2000; de ellas, 649 se encontraban en situación de disponibilidad (CONAGUA, 2008, p. 31). Se clasifican en 37 regiones hidrológicas y 13 regiones hidrológico-administrativas, que son la base sobre la cual se ha diseñado la actual política de control y manejo del agua a escala nacional (Cotler, Garrido, Mondragón y Díaz, 2007).

Figura 1. Mapa de disponibilidad de agua y poblaciones indígenas de México, 2015

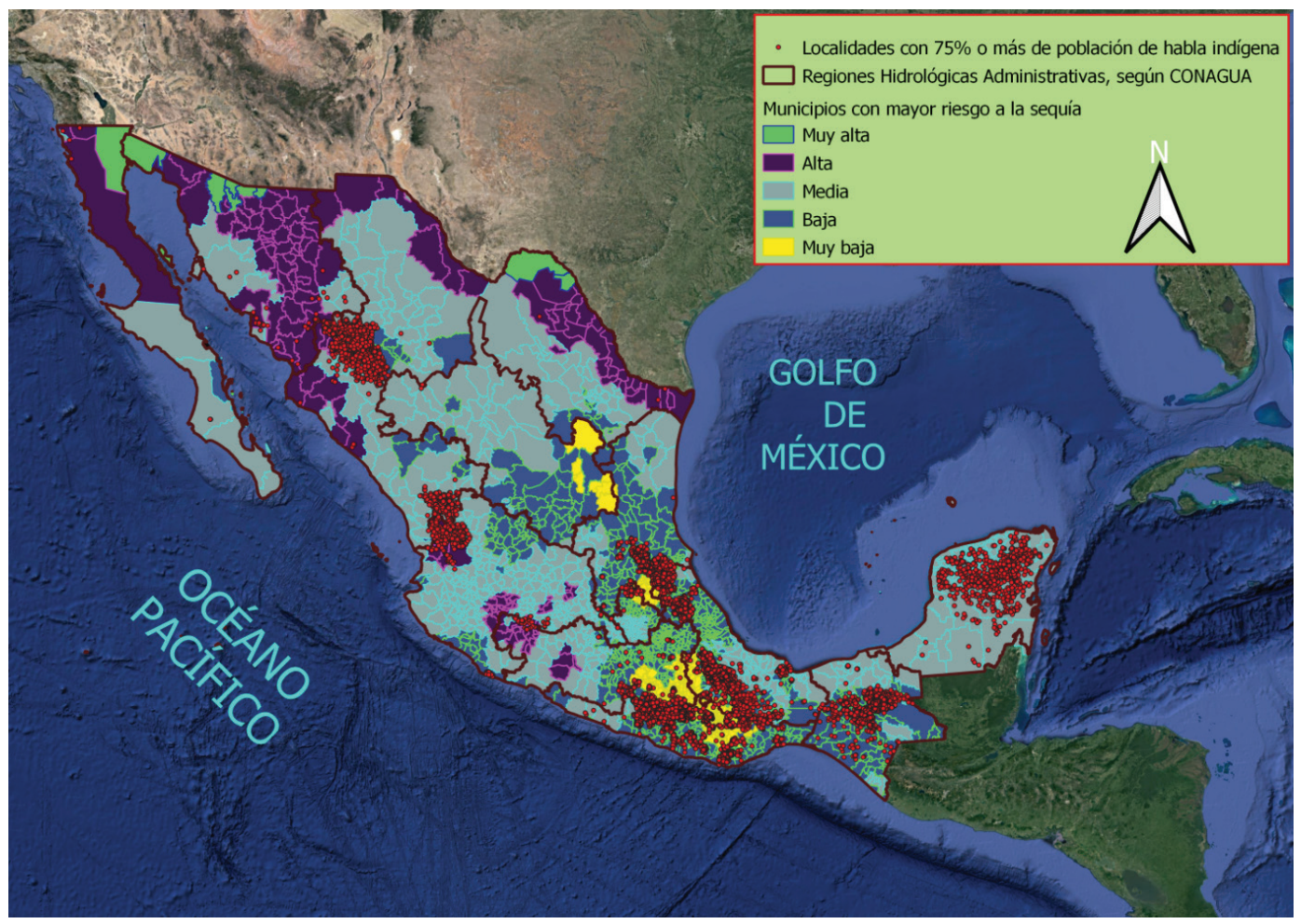

Fuente: elaboración propia con base en CONAGUA (1998 y 2015) y CONABIO (1999). 
Para representar lo dicho de manera gráfica, se han cruzado las bases de geolocalización de las localidades con $75 \%$ o más población hablante de una lengua indígena (Comisión Nacional para el Conocimiento y Uso de la Biodiversidad [CONABIO], 1999), con los polígonos de las cuencas hidrológicas (CONAGUA, 1998) y se señalan los municipios con mayor riesgo a la sequía (CONAGUA, 1998). El resultado de cruzar estas bases de datos se representa en la figura 1.

En la figura 1 se representan los municipios con mayor riesgo a la sequía con un color más oscuro, lo que permite apreciar que sobre todo se encuentran en el norte de México y que, de hecho, forman parte de las zonas áridas, semiáridas y desiertos de América del Norte.

Al sobreponer en el mapa la capa temática de distribución territorial actual de la población indígena, representada por los puntos rojos, se observa que la mayor parte no se encuentra en municipios con riesgo de sequía; por el contrario, se encuentran en una situación de abundancia del recurso hídrico, explicable por ser parte de tres rutas de huracanes y tormentas tropicales: la del océano Pacífico, la del golfo de México y la del mar Caribe y el sur-sureste forma parte de los bosques y selvas tropicales de Centroamérica, también conocida como Mesoamérica.

Lo anterior permite asegurar que, en México, las cuencas hidrológicas con menor riesgo de sequía están habitadas por pueblos indígenas, de manera particular en las cabezas de cuenca y de manera general en el sur-sureste. La historia de ocupación de cada región indígena se remonta a siglos, incluso milenios, por lo que se les reconoce como territorios donde se han asentado comunidades organizadas de forma compleja con sus rasgos, costumbres, prácticas y culturas tecnológicas propias (Hernández-Garciadiego, 2005). Sin embargo, las observaciones en campo y la revisión etnográfica (Villagómez, Amoroz y Gómez, 2013) han permitido constatar las difíciles condiciones de acceso al agua de calidad para consumo humano. A las mismas conclusiones llegan otros estudios en los que se calcula que más de $20 \%$ del agua de lluvia captada en México se ubica en los pueblos indígenas:

En los territorios de los pueblos indígenas de México se captan anualmente $364387.47 \mathrm{~mm}^{3}$ de agua en promedio anual. Esta cifra comparada con la captación nacional, que es de $1566301.39 \mathrm{~mm}^{3}$, significa 23.3\% del total nacional [...]. En su mayoría, los territorios de los pueblos indígenas se ubican en las cabezas de cuencas [...], es decir, donde se captura el agua y adquiere la mayor velocidad en el escurrimiento, y que reciben un impacto directo de eventos extraordinarios, como los huracanes o tormentas tropicales. (Boege, 2008, pp. 93-94)

Una información de la CONAGUA (2007) permite reforzar este dato al observar que tanto la población como la actividad económica en México se distribuyen en relación inversa con la disponibilidad de agua, pues menos de la tercera parte del escurrimiento superficial tiene lugar en una superficie equivalente a $75 \%$ del territorio, que es donde la disponibilidad de agua es menor y donde se concentra la mayor parte de los núcleos de población, las industrias y las tie- 
rras de riego, que representan áreas de producción agrícola significativa para el abastecimiento de mercados locales y para la agroexportación (CONAGUA, 2007).

Del total del agua que se aprovecha de las corrientes superficiales y de los mantos freáticos, $61 \%$ se destina a la energía eléctrica, con un volumen promedio de $116.5 \mathrm{~km}^{3}$ que genera $27600 \mathrm{GWh}$ de energía eléctrica. Puesto que esta agua no se consume, vuelve a su cauce casi en su totalidad reincorporándose a las corrientes superficiales. Como veremos en la siguiente sección, la construcción de grandes presas ha originado en reiteradas ocasiones el desplazamiento de las poblaciones indígenas.

\section{Las presas hidroeléctricas y los pueblos indígenas}

La planeación y la construcción de importantes obras de infraestructura hidráulica, como las presas Infiernillo (Michoacán y Guerrero), Malpaso, La Angostura y Chicoasén (Chiapas) o como la construcción de Río Escondido (Coahuila), la primera planta carboeléctrica del país, son parte del vigoroso impulso que se le dio al desarrollo e incremento de la infraestructura hidráulica nacional en las postrimerías de la Revolución mexicana de 1910.

En ese entonces se consideraba que era la estrategia más adecuada para abrir una significativa superficie de riego para la agricultura y producir los alimentos necesarios para satisfacer las necesidades de la población del país. Ya habían sido construidas en México varias obras hidráulicas de importancia, como la presa Necaxa (Puebla), terminada en 1909, para suministro de electricidad a la Ciudad de México, y la presa La Boquilla sobre el río Conchos (Chihuahua), que empezó a operar en 1916 para la generación de electricidad y para el riego (México Desconocido, 2010).

En 1926 fue creada la Comisión Nacional de Irrigación, que en ese mismo año inició la construcción de la presa de arco Plutarco Elías Calles (Aguascalientes), terminada cinco años más tarde, así como la Venustiano Carranza (también conocida como Don Martín) en Coahuila; ésta última con una característica novedosa: el vertedor de demasías fue equipado con 24 compuertas de funcionamiento automático. Dos años más tarde, en 1928, se iniciaron las obras de la presa Abelardo L. Rodríguez (Tijuana, Baja California), cuya construcción debió enfrentar dificultades importantes de origen geológico que la hicieron famosa fuera del país. Estas últimas tres presas fueron construidas por empresas estadounidenses y en ellas participaron pequeños grupos de ingenieros mexicanos (México Desconocido, 2010).

Otros ejemplos más recientes de construcción de grandes presas en México son las de Aguamilpa (Nayarit) sobre el río Santiago, próxima a su desembocadura en el Pacífico, y Huites (Sinaloa) sobre el río El Fuerte. Ambas obras tienen propósitos múltiples: generación hidroeléctrica, control de avenidas e irrigación. En la actualidad existen poco menos de 5000 presas en el país cuya altura oscila entre 5 y 265 metros. Entre ellas, la de mayor capacidad de almacenamiento es La Angostura (Chiapas), sobre el río Grijalva, pues puede contener 
hasta $18 \mathrm{~km}^{3}$ de agua, lo que equivale a más de dos veces el agua del lago de Chapala, que es de $8 \mathrm{~km}^{3}$, por lo que resulta el cuerpo de agua más grande de México (México Desconocido, 2010).

La Comisión del Papaloapan fue creada en 1947 durante el gobierno de Miguel Alemán y fue la encargada de la construcción de la presa de Temascal o presa Miguel Alemán, que en su momento era la más grande de América Latina. La región Mazateca Baja fue la más afectada, pues 55000 hectáreas de su territorio se inundaron y 22000 mazatecos tuvieron que ser reubicados. Una tercera parte de la población desplazada logró permanecer en los nuevos lugares de residencia que les fueron asignados. El resto prefirió regresar a la zona de la presa e iniciar un difícil proceso de readaptación a las nuevas condiciones ecológicas, económicas y sociales de su antiguo hábitat. El proyecto se terminó en 1986, con la inauguración de otra presa, llamada Miguel de la Madrid o presa Cerro de Oro, que ampliaba la capacidad del embalse.

El modelo de desarrollo entendido como complejo industrial o como "polo", en detrimento de los recursos naturales en regiones indígenas, también ha presentado sus complicaciones, como ocurrió en la región nahua de Pajapan, Veracruz, donde el desarrollo petrolero e industrial se ha concretado en la creación

Tabla 1. Pueblos indígenas desplazados por presas hidroeléctricas en México, 1949-1990

\begin{tabular}{|c|c|c|c|c|}
\hline Estado & Presa & $\begin{array}{c}\text { Pueblos } \\
\text { indígenas afectados }\end{array}$ & $\begin{array}{l}\text { Fecha de } \\
\text { reacomodo }\end{array}$ & $\begin{array}{l}\text { Población } \\
\text { afectada }\end{array}$ \\
\hline Oaxaca & Temascal & $\begin{array}{l}\text { Mazatecos y } \\
\text { Chinantecos }\end{array}$ & 1949-1954 & 22000 \\
\hline Sonora & El Novillo & & 1961 & 10000 \\
\hline $\begin{array}{l}\text { Michoacán } \\
\text { y Guerrero }\end{array}$ & El Infiernillo & & 1962 & 5500 \\
\hline Chiapas & La Angostura & $\begin{array}{l}\text { Tzotziles y } \\
\text { mestizos }\end{array}$ & 1972 & 15483 \\
\hline Oaxaca & Cerro de Oro & $\begin{array}{l}\text { Chinantecos } \\
\text { y mazatecos }\end{array}$ & 1974-1989 & 25000 \\
\hline Chiapas & Manuel Moreno Torres & & 1981 & 665 \\
\hline Chiapas & Peñitas & & 1983 & 1899 \\
\hline Guerrero & Carlos Ramírez Ulloa & Nahuas & 1984 & 5000 \\
\hline Chiapas & Itzantún & Zoques & 1986 & 13000 \\
\hline Nayarit & Aguamilpa & Huicholes & 1990 & 12450 \\
\hline $\begin{array}{l}\text { Hidalgo y } \\
\text { Querétaro }\end{array}$ & Zimapán & $\begin{array}{l}\text { Pames y } \\
\text { otomíes }\end{array}$ & 1990 & 2109 \\
\hline \multirow[t]{2}{*}{ Sinaloa } & Luis Donaldo Colosio & Mayos & 1991 & \\
\hline & & & Total & 113106 \\
\hline
\end{tabular}

Fuente: Gálvez (2004, p. 110). 
del puerto industrial de la Laguna del Ostión, que ha reducido su mundo de agua y montaña a una aglomeración de cemento y máquinas, como pasó en la región de los nahuas de Minatitlán y Coatzacoalcos. El proceso de construcción de diferentes industrias ubicadas en Jáltipan, Cosoleacaque, en el sur de Veracruz, provocó una gran concentración urbana y una segregación espacial que expulsó a los pueblos indígenas de la región que siempre habían ocupado. El impacto del crecimiento urbano-industrial en los ecosistemas locales ha convertido la cuenca del río Coatzacoalcos en una de las cuencas más contaminadas del país, después de la del río Lerma-Santiago.

La construcción de grandes presas ha provocado muchos problemas ecológicos, pues afectan el hábitat al que pertenecen especies faunísticas y vegetales, y perjudican a la población aledaña al lago superficial. Las áreas de relocalización donde se han ubicado las personas desplazadas, por lo general están lejos de sus lugares de origen. Además, es difícil restituirles las tierras de labor perdidas.

Hay poca información oficial, pero es sabido que, en repetidas ocasiones, en nombre del desarrollo, numerosos pueblos indígenas en cuyos territorios se encuentran estos recursos hídricos han sido afectados y a veces han desaparecido. La información más actualizada y precisa sobre la población indígena desplazada por la construcción de grandes presas hidroeléctricas, se observa en la tabla 1.

Las evidencias en campo indican que hay muchos procesos de desplazamiento por la construcción de grandes presas que no están incluidos en esta lista; sin embargo, es la única que se conoce públicamente y aun cuando incluye información limitada, el total estimado no deja de ser alarmante, pues se trata de al menos 12 grandes presas hidroeléctricas construidas entre 1949 y 1991 que provocaron la reubicación forzada de más de 113000 personas integrantes de pueblos indígenas de México.

Es importante señalar que la información de la tabla anterior no es precisa: el proyecto de construcción de la presa Itzantún se suspendió de manera indefinida por presiones de los pueblos zoques amenazados con ser desplazados. En esta información, que se dio a conocer (Gálvez, 2004) durante el seminario Desplazados Internos en México, llevado a cabo en Tlaxcala el 30 y el 31 de enero de 2004, los nombres de las presas están incompletos, algunas celdas de la base de datos están vacías y la cronología se detiene en 1991. ¿Qué hay detrás de esos vacíos de información?

Consideramos que se ocultó información de manera deliberada puesto que la persona que difundió los datos, la ingeniera Xóchitl Gálvez, fue invitada al evento en su calidad de directora de la Comisión Nacional para el Desarrollo de los Pueblos Indígenas (CDI) y cuidó mucho lo que divulgaba para evitar comprometer el Estado mexicano. Podemos afirmar esto por el hecho de que la cronología de afectaciones a los pueblos indígenas por la construcción de presas se interrumpe en 1991 y no llega a 2004. No es casualidad: en 1991 México ratifica el Convenio 169 de la Organización Internacional del Trabajo (OIT), en el que expresamente se reconocen los derechos de los pueblos indígenas al territorio, a la identidad, a los recursos naturales y a la consulta previa, libre e informada. 
Antes del Convenio 169, el paradigma de derechos indígenas en México estaba regido por el Convenio 107, también de la OIT. La diferencia es notable, pues en el Convenio 107 los Estados se comprometían a integrar a los pueblos indígenas al desarrollo nacional mediante proyectos, y en el Convenio 169 los Estados se ven obligados a reconocer a los pueblos y sus territorios, y a consultarles antes de la ejecución de obras de infraestructura que pudieran afectarles.

La diferencia entre ambos convenios es notoria. Es un cambio de paradigma y, al parecer, la entonces directora de la CDI ocultó información acerca de los pueblos indígenas afectados entre 1991 y 2004, esto es, durante la vigencia del Convenio 169. Ampliar la información habría dado a dichos pueblos la oportunidad, a través de sus representantes, de demandar al Estado por incumplimiento del Convenio 169. Para evitar controversias, la divulgación de los datos de población indígena desplazada por la construcción de presas se limitó al periodo anterior al tratado internacional por el principio de no retroactividad de las leyes.

Considerando la dificultad para contar con información precisa acerca del desplazamiento forzado de los pueblos indígenas, ¿para qué incluir la tabla anterior en este artículo? Para señalar que es la única información oficial difundida. Los datos precisos y actualizados acerca del número de personas desplazadas por la construcción de presas hidroeléctricas no han sido difundidos en ningún otro documento oficial.

La construcción de grandes presas - cuyo volumen de almacenamiento es mayor a $300 \mathrm{~m}^{3}$, es decir, tres hectómetros cúbicos $\left(\mathrm{hm}^{3}\right)$ según la Comisión Internacional de Grandes Presas (ICOLD) (CONAGUA, 2018, p. 105) - no sólo ha motivado el desplazamiento de la población indígena, sino también del grupo demográfico dominante en México, el mestizo.

Olvera-Molina (2011, p. 85) calcula que en el periodo de 1936 a 2006 fueron desplazadas hasta 180000 personas por dichas obras, esto es, 50000 personas más que las que se consignan en la información oficial. Evidentemente, una tesis académica no puede remplazar la información oficial, pero nos aproxima a dimensionar el problema de desplazamiento por la construcción de presas en los territorios indígenas. Éste es el resultado de la aplicación de una política que, siguiendo un supuesto beneficio para la nación, despoja a los grupos más vulnerables de sus territorios.

\section{El agua en disputa}

El agua es un recurso inserto en un contexto más amplio de disputa por los recursos naturales en los últimos años, sobre todo por los proyectos de inversión en las grandes obras de infraestructura que han provocado un impacto considerable en los ecosistemas de los territorios indígenas ricos en biodiversidad. Se han afectado también las culturas y las formas de organización tradicionales, ante lo cual diferentes organizaciones ecologistas y movimientos indígenas en diversos lugares del país han explicitado su interés en defender el medio ambiente y reivindicar el derecho de aprovechamiento de estos recursos como bien común. 
La participación de la sociedad civil en organizaciones de usuarios de agua ha permitido a barrios urbanos y comunidades rurales orientar la demanda de agua hacia una gestión más democrática del recurso y también ha generado formas de organización social con base en redes solidarias que los llevan a incidir en problemas que el Estado no ha podido resolver, como el acceso y el saneamiento oportuno del recurso. Queda pendiente resolver la manera de "encontrar y construir las formas y los canales institucionales para confrontar y dirimir nuestras diferencias y llegar a consensos para una gestión sustentable e integral del agua" (Torregrosa y Kloster, 2018).

En el escenario social, de manera reciente se ha constituido el Movimiento Mexicano de Afectados/as por las Presas y en Defensa de los Ríos (MAPDER) para protestar en contra de la construcción de las presas que se teme dañen los territorios indígenas y los recursos de otras localidades rurales. Entre los casos más emblemáticos que se han identificado, se pueden mencionar La Parota (Guerrero), Arcediano (Jalisco), La Línea, El Porvenir, Isla El Cayo, Boca del Cerro (Tabasco), Aguamilpa y El Cajón (Nayarit), Benito Juárez, Miguel Alemán y Cerro de Oro (Oaxaca), Huixtán I, Huixtán II, Quetzalli, Altamirano-Nance, Sistema Cancuc, Itzantún, Yaxchilán (Chiapas), Cañón de la Cabeza y Tigre (Coahuila) y El Zapotillo (para abastecer de agua a la ciudad de León, Guanajuato, a la región de Los Altos de Jalisco y a la ciudad de Guadalajara) (Castro, 2006). Se pueden añadir Paso de la Reina (Oaxaca), La Yesca (Jalisco), Las Cruces (Nayarit), Itzantún y Chinín (Chiapas), Pantanos de Centla (Tabasco), por mencionar los más conocidos (Chávez-Galindo, 2010).

El escenario que se presenta ante la creciente conflictividad y la disputa por el agua obliga a establecer estrategias de control y equidad para que los distintos usuarios tengan acceso al agua y se establezcan dispositivos de organización para un aprovechamiento racional, en el sentido de controlar el desperdicio o la contaminación de agua, y al mismo tiempo que puedan instaurar estrategias de conservación de las fuentes de aprovisionamiento a escala local, regional y nacional.

Puede argumentarse que el agua, su manejo y la conservación de sus fuentes de aprovisionamiento permiten generar políticas de desarrollo social a escala regional, pero también es importante considerar que pueden afectar de manera irreversible los patrones sociales y la cultura local. Ésta es una realidad sobre la que hay que llamar la atención para crear políticas de manejo del agua en coordinación con las poblaciones y sus intereses en los territorios de donde el Estado extrae los recursos económicos necesarios para las obras que conllevan los grandes proyectos de inversión. Sobre todo hay que tomar en cuenta las concesiones a las empresas mineras y a las constructoras que realizan trasvases de una cuenca a otra con el objetivo de abastecer las ciudades, ya que se parte del principio de que sin agua las actividades productivas no tendrían buenos resultados ni beneficios para la población.

Desde la etapa de formación de las comisiones hidrológicas se ha considerado a las cuencas hidrográficas como los territorios más apropiados para orientar los procesos de manejo, aprovechamiento, planeación y administración del agua y, en su sentido más amplio y general, como los idóneos para llevar a cabo la gestión integral de los recursos hídricos. 
Las dinámicas de organización territorial de los pueblos indígenas a partir de su estructura agraria permiten advertir que el nivel más cercano a la realidad social de los pueblos no son las grandes regiones, como las cuencas hidrográficas que la CONAGUA ha definido con fines administrativos, sino las microcuencas hidrográficas, cuya delimitación obedece a los acuerdos de gestión de los recursos hídricos de colonias, ejidos, comunidades, pueblos y, en el nivel más complejo, de los municipios. Es decir que, si hay un modelo idóneo para la gestión del agua a través del sistema de cuencas, éste lo encontramos en las microcuencas.

El modelo basado en las microcuencas tendría que ser lo suficientemente flexible y adaptable en tamaño según la capacidad de organización de los pueblos indígenas, de tal manera que si un pueblo logra una capacidad de gestión del territorio que abarque varias microcuencas, tendría que ser catalogado como comité de cuenca, aun cuando los límites hidrológicos de una cuenca no coincidan con los de una comunidad agraria o una organización indígena. El criterio es que los lindes de las cuencas no deben limitar la capacidad de gestión del territorio basada en la experiencia de los pueblos y sus representantes.

La cuenca, además de ser donde se verifica el ciclo hidrológico, es el espacio geográfico donde los grupos y las comunidades comparten identidades, tradiciones y cultura. Ahí socializan y trabajan los seres humanos en función de la disponibilidad de recursos renovables y no renovables.

\section{Hacia una política intercultural en la gestión del agua}

La Oficina del Alto Comisionado de las Naciones Unidas para los Derechos Humanos (OACNUDH) vigila, a través de los relatores especiales en materia de agua y saneamiento y de los relatores en materia de los derechos de los pueblos indígenas, los derechos colectivos de los pueblos indígenas, entre ellos el derecho humano al agua y a un medio ambiente sano para su desarrollo y bienestar. Aunque reconocen los alcances por parte del Estado, en su visita oficial a México, ambos relatores documentaron casos en diferentes estados de la república mexicana que son muy preocupantes y que se resumen en la tabla 2.

En 2007 la Asamblea General de la ONU aprobó la Declaración sobre Derechos de los Pueblos Indígenas, en la que se reconocen los derechos colectivos de éstos, entre ellos los de autonomía y libre determinación y el de acceso, uso y disfrute de los recursos naturales existentes en sus territorios. También en esa declaración se asienta la obligación de los Estados nacionales de facilitar el enfoque intercultural en la planeación y en la ejecución de las políticas públicas y de los programas de desarrollo (ONU, 2007). Tres años después, el mismo organismo aprobó una resolución en la que se contempla el derecho humano al agua y al saneamiento (ONU, 2010).

Ambas resoluciones fueron suscritas por México, aunque no se tradujeron en ratificaciones del Senado o en decretos que se publicaran en el Diario Oficial de la Federación (DOF) debido a que no son tratados internacionales, sino acuerdos resolutivos de reuniones internacionales. Sin embargo, son compromisos 
Tabla 2. Casos de violación al derecho humano al agua y saneamiento en los pueblos indígenas de México, identificados por los relatores de la Organización de las Naciones Unidas (ONU) en sus visitas oficiales

\begin{tabular}{|c|c|c|c|c|}
\hline $\begin{array}{l}\text { Pueblos } \\
\text { indígenas }\end{array}$ & Ubicación & Cuenca o río & $\begin{array}{c}\text { Derechos } \\
\text { colectivos } \\
\text { violentados }\end{array}$ & $\begin{array}{c}\text { Informe de los relatores } \\
\text { de la ONU en que se } \\
\text { observa }\end{array}$ \\
\hline $\begin{array}{c}\text { Cucapás } \\
\text { versus Decreto } \\
\text { de veda } \\
\text { pesquera }\end{array}$ & $\begin{array}{c}\text { Baja } \\
\text { California }\end{array}$ & $\begin{array}{l}\text { Delta del río } \\
\text { Colorado } \\
\text { y alto golfo } \\
\text { de } \\
\text { California }\end{array}$ & $\begin{array}{c}\text { Restricciones a } \\
\text { sus actividades } \\
\text { económicas de } \\
\text { pesca, acoso } \\
\text { judicial }\end{array}$ & $\begin{array}{l}\text { Consejo Económico y } \\
\text { Social de las Naciones } \\
\text { Unidas (NU) ( } 23 \text { de } \\
\text { diciembre de } 2003 \text { ) } \\
\text { E/CN4/2004/80/Add2 }\end{array}$ \\
\hline $\begin{array}{l}\text { Miles de } \\
\text { comunidades } \\
\text { menores } \\
\text { de } 15000 \\
\text { habitantes }\end{array}$ & $\begin{array}{l}\text { Situación } \\
\text { generalizada } \\
\text { en } \\
\text { poblaciones } \\
\text { indígenas }\end{array}$ & $\begin{array}{c}\text { Todo el país, } \\
\text { con } \\
\text { evidencias } \\
\text { en Chiapas } \\
\text { y Estado de } \\
\text { México }\end{array}$ & $\begin{array}{l}\text { Deficientes } \\
\text { servicios de } \\
\text { agua potable } \\
\text { y saneamiento }\end{array}$ & $\begin{array}{c}\text { Oficina del Alto } \\
\text { Comisionado para los } \\
\text { Derechos Humanos } \\
\text { (2 de agosto de 2017) } \\
\text { A/HRC/36/45/Add2 } \\
\text { Oficina del Alto } \\
\text { Comisionado para los } \\
\text { Derechos Humanos } \\
\text { (28 de junio de 2018) } \\
\text { A/HRC/39/17/Add2 }\end{array}$ \\
\hline $\begin{array}{c}\text { Yaquis versus } \\
\text { Proyecto } \\
\text { Acueducto } \\
\text { Independencia }\end{array}$ & Sonora & Río Yaqui & $\begin{array}{c}\text { Territorio, } \\
\text { consulta, acceso } \\
\text { y disfrute del } \\
\text { medio ambiente } \\
\text { del río }\end{array}$ & $\begin{array}{c}\text { Organización de las } \\
\text { Naciones Unidas (19 de } \\
\text { julio de 2019) A/74/197 } \\
\text { Oficina del Alto } \\
\text { Comisionado para los } \\
\text { Derechos Humanos } \\
\text { (28 de junio de } 2018 \\
\text { A/HRC/39/17/Add2 }\end{array}$ \\
\hline $\begin{array}{l}\text { Mayas de } \\
\text { Campeche } \\
\text { versus plantíos } \\
\text { de soya (soja) } \\
\text { transgénica }\end{array}$ & Campeche & Candelaria & $\begin{array}{l}\text { Contaminación } \\
\text { de agua por } \\
\text { herbicidas, salud } \\
\text { ambiental, } \\
\text { patrimonio } \\
\text { biocultural, } \\
\text { agricultura y } \\
\text { apicultura } \\
\text { tradicional, } \\
\text { consulta y } \\
\text { consentimiento } \\
\text { previo }\end{array}$ & $\begin{array}{l}\text { Oficina del Alto } \\
\text { Comisionado para los } \\
\text { Derechos Humanos } \\
\text { (28 de junio de 2018) } \\
\text { A/HRC/39/17/Add2 }\end{array}$ \\
\hline $\begin{array}{c}\text { Rarámuris ver- } \\
\text { sus } \\
\text { proyecto } \\
\text { turístico } \\
\text { Barrancas del } \\
\text { Cobre }\end{array}$ & $\begin{array}{l}\text { Municipios } \\
\text { Urique y } \\
\text { Bocoyna, } \\
\text { Sierra } \\
\text { Tarahumara, } \\
\text { Chihuahua }\end{array}$ & $\begin{array}{l}\text { Río Urique, } \\
\text { afluente } \\
\text { de la } \\
\text { cuenca del } \\
\text { río Fuerte }\end{array}$ & $\begin{array}{c}\text { Contaminación de } \\
\text { fuentes de agua } \\
\text { por } \\
\text { descargas de } \\
\text { aguas residuales } \\
\text { y de basura de } \\
\text { los hoteles }\end{array}$ & $\begin{array}{l}\text { Oficina del Alto } \\
\text { Comisionado para los } \\
\text { Derechos Humanos } \\
\text { (28 de junio de 2018) } \\
\text { A/HRC/39/17/Add2 }\end{array}$ \\
\hline Tsotsiles & $\begin{array}{c}\text { Ejido La } \\
\text { Candelaria, } \\
\text { municipio } \\
\text { San } \\
\text { Cristóbal de } \\
\text { Las Casas, } \\
\text { Chiapas }\end{array}$ & $\begin{array}{c}\text { Microcuenca } \\
\text { del valle de } \\
\text { Jovel, } \\
\text { Cuenca } \\
\text { del río } \\
\text { Grijalva }\end{array}$ & $\begin{array}{c}\text { Acceso a la } \\
\text { Laguna, } \\
\text { contaminación }\end{array}$ & $\begin{array}{l}\text { Oficina del Alto } \\
\text { Comisionado para los } \\
\text { Derechos Humanos } \\
\text { (28 de junio de } 2018 \text { ) } \\
\text { A/HRC/39/17/Add2 }\end{array}$ \\
\hline
\end{tabular}

Fuente: elaboración propia. 
internacionales exigibles, es decir, que la ciudadanía puede reivindicarlos en la demanda de derechos, como de hecho ha ocurrido desde hace décadas. En 2012 el Congreso aprobó agregar un corto párrafo al artículo IV de la Constitución Política de los Estados Unidos Mexicanos. Quedó como sigue:

Toda persona tiene derecho al acceso, disposición y saneamiento de agua para consumo personal y doméstico en forma suficiente, salubre, aceptable y asequible. El Estado garantizará este derecho y la ley definirá las bases, apoyos y modalidades para el acceso y uso equitativo y sustentable de los recursos hídricos, estableciendo la participación de la Federación, las entidades federativas y los municipios, así como la participación de la ciudadanía para la consecución de dichos fines. (DOF, 6 de marzo de 2020)

El reconocimiento constitucional del agua y del saneamiento como derechos humanos es un gran avance en materia de derechos sociales; sin embargo, no se ha avanzado más en la materia y queda pendiente la ley reglamentaria que haga justicia a estos derechos, por lo que en realidad es tan sólo un marco jurídico para justificar los programas de inversión en sistemas de agua potable y saneamiento que ya existían antes de esta reforma jurídica.

En 2013 el Congreso aprobó reformas a diversas leyes, entre ellas a la Ley de Aguas Nacionales, y expidió la Ley de Responsabilidad Ambiental. Dichas reformas otorgaron mayores facultades a la CONAGUA (DOF, 1 de diciembre de 1992a, Art. 96 bis), a la Procuraduría Federal de Protección Ambiental (PROFEPA) e incluyeron mecanismos para hacer exigibles las resoluciones judiciales en materia de responsabilidad por daño, contaminación, deterioro y afectaciones al medio ambiente en general y a los ecosistemas asociados con el agua en particular (DOF, 7 de junio de 2013).

Un año después de decretarse esta importante legislación en materia ambiental, se aprobó una reforma energética muy profunda, que incluyó dos leyes nuevas que tienen implicaciones en los recursos hídricos en territorios indígenas: la Ley de Energía Geotérmica y la Ley de Hidrocarburos.

La Ley de Energía Geotérmica incluye aguas geotérmicas, que son las que se encuentran en volcanes o yacimientos geotérmicos a temperaturas de 80 grados Celsius y que no son aptas para el consumo humano. Ahí se declara el uso preferente para "la explotación geotérmica sobre cualquier otro uso o aprovechamiento del subsuelo de los terrenos, salvo que se trate de la industria de los hidrocarburos" (Art. 4). En el segundo párrafo del mismo artículo se incluye una salvaguarda vinculada al derecho de los pueblos indígenas a la consulta previa, libre e informada, así como el marco de respeto a los derechos humanos y sociales de los particulares, ejidatarios, comuneros o dueños de los predios de que se trate (DOF, 11 de agosto de 2014a).

La Ley de Hidrocarburos, por su parte, se refiere a la industria del petróleo, el gas y la petroquímica. Establece una salvaguarda para los pueblos indígenas en el artículo 100, párrafo segundo, en la cual se advierte que para el uso de terrenos para actividades de exploración y extracción de hidrocarburos se apli- 
carán "los derechos que la Constitución, las leyes y los tratados internacionales suscritos por el Estado mexicano que reconocen a las comunidades indígenas", sin mencionar a qué legislación en específico se refiere, por lo que se trata de un derecho difuso, sujeto a la interpretación de las autoridades administrativas o judiciales (DOF, 11 de agosto de 2014b).

En la Ley Minera no se establece ningún tipo de salvaguarda para los pueblos indígenas; más bien se los incluye entre los posibles beneficiarios de las concesiones de exploración y explotación de minerales, sustancias, sales y subproductos de éstas (DOF, 26 de junio de 1992b). Existen concesiones mineras a favor de comunidades agrarias, ejidales, comunales y de pueblos indígenas, sobre todo de granito y ámbar. Estos últimos han hecho público su rechazo a las grandes concesiones mineras, porque derivan en daños y conflictos ambientales, debido al impacto que tienen en los recursos hídricos y forestales.

Este cuerpo de leyes de exploración y explotación de minería, hidrocarburos y energía geotérmica ha originado un nuevo tipo de daños al medio ambiente en regiones indígenas que poseen este tipo de recursos en el subsuelo. La construcción de grandes obras de infraestructura, como las presas hidroeléctricas, las carreteras, los complejos urbano-industriales y los aeropuertos, entre otras, también producen disputas.

Para la ejecución de proyectos que impliquen la trasformación del paisaje en los territorios indígenas, la extracción de los recursos hídricos, minerales o de hidrocarburos, e incluso de otros recursos como los eólicos, la Suprema Corte de Justicia de la Nación (SCJN) ha emitido un protocolo de actuación que incluye principios jurídicos que habrán de seguir los jueces que tengan que dirimir conflictos entre pueblos indígenas, agencias del Estado o inversionistas. Entre dichos principios están los que atañen a las etapas de planeación y ejecución de los proyectos: el derecho al debido proceso, a la información, a la participación y a la consulta previa, libre, informada y de buena voluntad.

En el caso de que alguno de esos derechos sea violentado y se originen conflictos socioambientales, los juzgadores habrán de velar por el respeto a los derechos a la libre expresión, a la protesta, a la reunión, a la asociación y a la protección contra la criminalización.

El mismo protocolo de la SCJN establece como indicadores de acceso al desarrollo por parte de los pueblos indígenas un piso mínimo de servicios y de beneficios que no podrán ser violentados por la ejecución de grandes obras de infraestructura o por concesiones de exploración o explotación de los recursos en sus territorios, entre ellos, el derecho a una vivienda adecuada, a una alimentación sana, variada y suficiente, al agua y al saneamiento, a la salud, a la reproducción de su cultura, a la educación y a un medio ambiente sano (SCJN, 2014).

Puesto en juego este marco de derechos colectivos de los pueblos indígenas en lo que se refiere al agua, México tiene una cobertura de $94 \%$, y de infraestructura de saneamiento o drenaje de $93 \%$, según reportaron agencias del Estado al Relator Especial de la ONU en su visita oficial en mayo de 2017. Es importante mencionar que, en su informe, el Relator expresó preocupación por los casos de las comunidades indígenas que carecen de acceso a fuentes limpias 
de agua y dependen de pozos, ríos, manantiales o lagunas, muchas veces contaminados por desechos fecales de las viviendas o de ganado. La exposición de la población a aguas residuales está asociada con diarreas, vómitos, jaquecas, dermatitis, infecciones oculares (Oficina del Alto Comisionado para los Derechos Humanos, 2 de agosto de 2017).

Según el censo de población realizado en 2010 , hasta $62 \%$ de la población indígena se encuentra en localidades rurales con menos de 2500 habitantes. Se calcula que $72 \%$ de ésta ( 8.2 millones) vive en pobreza y $27 \%$ en pobreza extrema (Centro de Estudios para el Desarrollo Rural Sustentable y la Soberanía Alimentaria [CEDRSSA], 2015). Los datos correspondientes a la disponibilidad de servicios de agua entubada, drenaje y electricidad en viviendas de poblaciones indígenas se ilustran en la figura 2.

Si bien la población indígena habita en las 32 entidades federativas de México, en Oaxaca, Chiapas, Veracruz, Yucatán, Puebla, México, Hidalgo, Guerrero, Quintana Roo, San Luis Potosí, Ciudad de México, Michoacán, Campeche, Chihuahua, Sonora y Tabasco, ésta rebasa los 120000 habitantes por estado.

Con un total cercano a 2.4 millones de viviendas indígenas, 2.2 de éstas cuentan con servicios de electricidad, pero no con acceso a otros servicios derivados de la gestión del agua: 1.5 millones disponen de drenaje en la vivienda y 1.7 millones, de agua entubada, de servicios básicos para una vida digna y de condiciones de saneamiento (Instituto Nacional de Estadística y Geografía [INEGI], 2010).

Dada la irregular distribución del agua en el territorio nacional, la CONAGUA justifica la construcción de obras para satisfacer la demanda de ésta y, por tal motivo, en las zonas áridas del país se han construido presas para riego. En las regiones húmedas se han erigido cerca de 4500 estructuras para el almacenamiento de agua y para generar energía hidroeléctrica.

Un elemento importante que hay que agregar son los efectos que sobre los acuíferos y las aguas superficiales tiene la contaminación, provocada sobre todo por las descargas sin control de aguas residuales. Las autoridades deben regular los permisos para realizar dichas descargas en corrientes superficiales. Sin embargo, no resuelven la cuestión, sino que cambian de lugar los problemas de contaminación. La situación tiende a agravarse en la medida en que se incrementa la densidad poblacional en algunas regiones del país que funcionan como polos de atracción de mano de obra.

Cabe mencionar que si bien los problemas de salud derivados del uso de aguas residuales para labores domésticas o consumo humano, por falta de infraestructura de agua limpia y saneamiento adecuado, están presentes tanto en zonas rurales como urbanas, en este artículo se quiere destacar la gravedad del caso para los pueblos y las comunidades indígenas.

Es relevante tomar en cuenta el informe de la visita oficial de la Relatora Especial de la ONU en materia de derechos de los pueblos indígenas, Victoria Tauli-Corpuz, en junio de 2018, en especial en lo que se refiere a la violación del derecho humano al agua para los pueblos indígenas, entre los que se destacan los siguientes casos: el ejido La Candelaria, municipio San Cristóbal de Las Casas, Chiapas, en el extremo sureste de México, defiende una laguna en 


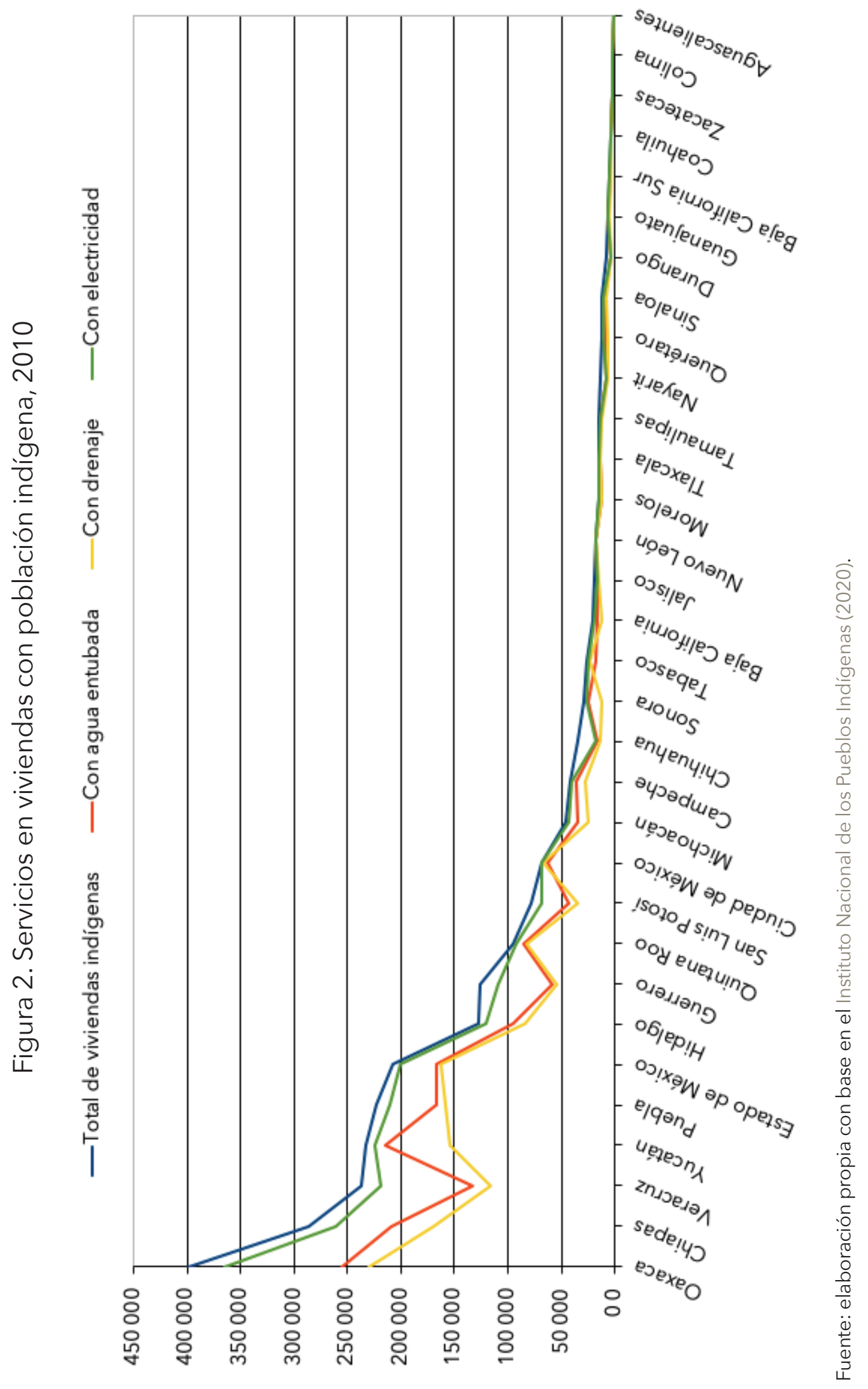


territorio sagrado y está en riesgo debido a la expansión de los proyectos turísticos, de carreteras y otros que "afectarían la integridad de la laguna y la continuación de sus prácticas culturales" (OACNUDH, 28 de junio de 2018). Otro conflicto que dicha Relatora documentó se ubica en la frontera norte del país. Corresponde a los pocos sobrevivientes de la cultura cucapá, en Baja California. Rodolfo Stavenhagen, el anterior Relator de derechos indígenas, identificó este caso en su visita oficial de 2003 (Consejo Económico y Social de las Naciones Unidas [NU], 23 de diciembre de 2003). Desde entonces consiste en dificultades legales a las que se enfrentan los cucapás para continuar con sus actividades tradicionales de pesca por el decreto de la Reserva de la Biosfera Alto Golfo de California y Delta del Río Colorado que restringe sus labores y que en lugar de contribuir a la protección de la fauna marina alienta la pesca clandestina (OACNUDH, 28 de junio de 2018b, párrs. 26-28; Bravo-Espinosa, 2018; Alarcón-Chaires, 2001).

En ese reporte se cita un documento de la Comisión Interamericana de Derechos Humanos $(\mathrm{CIDH})$, instancia judicial a la que ha llegado el clamor de los pueblos afectados por la minería: "de 29000 concesiones mineras, hidroeléctricas y de energía eólica que afectan 35\% del territorio nacional, $17 \%$ se encuentran en territorios indígenas" (CIDH, 2015; citado por OACNUDH, 28 de junio de 2018, párr. 31).

Un tema preocupante observado por diferentes organismos de derechos humanos de las Naciones Unidas es la criminalización de la protesta de los pueblos yaquis, opositores al acueducto Independencia en el río Yaqui (López-Bárcenas, 2018), pese a que la CIDH les ha brindado medidas cautelares (OACNUDH, 28 de junio de 2018b, párr. 48).

Además de los testimonios reportados por la Relatora en su visita de 2018, hay que destacar aquí el caso del Movimiento en Defensa de la Vida y el Territorio (MODEVITE), integrado por autoridades y pueblos indígenas de la zona norte de Chiapas, que llevó a cabo en 2017 movilizaciones multitudinarias contra las concesiones de exploración de pozos petroleros y de geotermia en las confluencias de los territorios zoques, tsotsiles y tseltales. También se distingue el movimiento de los pueblos a todo lo largo de la ruta Palenque-San Cristóbal de Las Casas contra el proyecto de la autopista en la misma ruta. El argumento en contra era que el trazo propuesto destruiría los ríos, los ojos de agua y los lugares sagrados: lagunas y cuevas que utilizan los pueblos tsotsiles, tseltales y choles para la reproducción de su cultura.

\section{Discusión}

Estos casos y otros, que no se incluyen debido a límites de espacio, son evidencias de que para los pueblos indígenas de México los usos del agua tienen una prioridad distinta a la sobreexplotación que de ella se hace para un fin económico y se puede afirmar que sus preferencias se concentran en garantizar, primero que nada, la reproducción social, económica y ambiental. Lejos de idealizar la organización, los intereses y las aspiraciones de las comunidades 
indígenas que en ciertos aspectos también incurren en prácticas consideradas no sustentables, como la ganadería extensiva, sí se considera aquí que siguen representando a un sector marginado de la sociedad y, con demasiada frecuencia, de la política de gestión de los recursos hídricos. Lo anterior ha generado, entre otras cosas, que estas comunidades continúen con un acceso limitado al recurso, que carezcan de asistencia técnica debido a que se considera que las poblaciones rurales no generan índices significativos de crecimiento para la economía del país, además de que se cae en el imaginario social expresado con el concepto de población pobre.

No obstante, se estima preciso apoyar y cambiar la política que hasta ahora se ha practicado. Debe entenderse que, en términos de la autosuficiencia alimentaria, del mejoramiento de la vida en el campo y de la solución a la pobreza de esta población, es recomendable introducir en la Ley de Aguas Nacionales y en los programas de acción de la CONAGUA cambios importantes en los que se contemple a este sector. No hacerlo significa entonces seguir permitiendo una condición de inequidad en el acceso al recurso.

Es importante destacar que al cierre de este artículo, México aún no ratifica la firma del Acuerdo Regional sobre el Acceso a la Información, la Participación Pública y el Acceso a la Justicia en Asuntos Ambientales en América Latina y el Caribe, conocido como Acuerdo de Escazú (Comisión Económica para América Latina, 2018) instrumento que, una vez que haya entrado en vigor, abrirá un nuevo capítulo en los procesos de exigibilidad y justiciabilidad de derechos ambientales y que puede ampliar las capacidades de organización de los pueblos indígenas en defensa de los recursos hídricos.

\section{Conclusiones}

Agua y saneamiento como derechos humanos

En cuanto al derecho humano al agua, se destaca la existencia de los casos de las poblaciones sin acceso a fuentes de agua de buena calidad para consumo humano, y que dependen de ríos, manantiales, pozos o lagunas para satisfacer sus necesidades domésticas, beber o asearse, lo que está asociado a la emergencia de enfermedades infecciosas en piel, estómago y ojos, por lo que se confirma el principio de que el agua es un derecho humano que permite obtener otros derechos, en este caso, el derecho a la salud.

\section{Conflictos por la construcción de obras}

La construcción de grandes obras de infraestructura, como presas hidroeléctricas, acueductos y carreteras, así como las actividades de exploración y explotación de minerales, petróleo o gas en territorios de los pueblos indígenas, derivan en situaciones de despojo y problemas socioambientales por contaminación, deterioro o desviación de recursos hídricos para proyectos de desarrollo que, además, alteran los sistemas tradicionales de reproducción social, económica y cultural de los pueblos indígenas. 
Conflictos por megaproyectos de desarrollo

En este tipo de afectaciones se pueden incluir los proyectos de desarrollo sustentable que se ejecutan sin que los pueblos indígenas tengan la garantía de acceso a los beneficios. Algunos ejemplos son los casos de conflicto por proyectos de ecoturismo en Chiapas o el caso de las áreas naturales protegidas decretadas en parte de los territorios indígenas las cuales generan un marco jurídico que restringe el acceso a las actividades de pesca tradicional, como el caso de los cucapás de Baja California y de los mayas de Campeche, los primeros en contra de las vedas pesqueras y los segundos en contra de los plantíos de soya transgénica.

\section{Derecho a la consulta}

Es lamentable encontrar testimonios de conflictos socioambientales, territoriales, por impacto de grandes obras de infraestructura y por imposición de decretos, concesiones, proyectos de desarrollo, complejos urbano-industriales o marcos normativos debido a que no se ha consultado a los pueblos indígenas ni se los ha incluido para el acceso y la distribución de beneficios, o no se ha respetado su derecho a la libre determinación para definir sus propios procesos de desarrollo.

\section{Agencias gubernamentales}

Con respecto a las agencias gubernamentales de desarrollo, destaca el caso de la CONAGUA en la gestión del agua en las cuencas hidrográficas y el de la CDI-Instituto Nacional de los Pueblos Indígenas (INPI) en la promoción del desarrollo de los pueblos y comunidades en regiones indígenas. La evidencia indica que la regionalización de estas y otras instituciones se hace con fines administrativos, de gestión y operación de los recursos financieros y no responde a los criterios de organización territorial de los pueblos.

\section{Ausencia de un enfoque intercultural}

Se está lejos de que la política hídrica en los territorios, pueblos y comunidades indígenas se caracterice por seguir un enfoque intercultural. Al respecto, tampoco hay una normativa específica que indique la transversalidad de este enfoque en las políticas públicas. Por ejemplo, en la legislación del agua y en los programas y políticas derivados sí se incluyen criterios de participación social para la gestión del agua, pero no se especifican mecanismos o dinámicas de participación de los pueblos indígenas a través de sus autoridades agrarias, mucho menos se incluye la obligación de considerar los sistemas de cargos u otros sistemas de gobierno tradicionales.

\section{Criterio preferencial en favor de los pueblos indígenas}

En la medida en que la gestión del agua en México es participativa, con base en los comités de cuenca y en las concesiones de agua a particulares, sería pertinente incluir un criterio de preferencia para los pueblos indígenas que les facilite el acceso a los recursos hídricos en sus territorios ancestrales. Esto implicaría que los pueblos y comunidades tengan un mayor acceso a los sistemas 
de agua potable, saneamiento y riego, lo que sería un acto de justicia que podría reducir las condiciones de pobreza y desigualdad. En la actualidad se están dando procesos de participación de organizaciones ciudadanas para hacer cambios importantes en una propuesta ciudadana para la Ley de Aguas Nacionales, lo cual es un acontecimiento sin precedente.

\section{Lecciones aprendidas}

La CONAGUA y otras agencias podrían flexibilizar su normativa para otorgar concesiones de agua o facilitar infraestructura de agua potable y saneamiento si se apoyaran más en las autoridades indígenas. No se puede seguir haciendo caso omiso de la participación de las organizaciones ciudadanas en el manejo y gestión de un recurso estratégico fundamental para los diversos sectores de usuarios de agua en el país.

\section{Agradecimientos}

Se agradece al ingeniero Edwin Cuellar Carrasco, de la Universidad Autónoma Chapingo sede Chiapas, por su apoyo en el diseño del mapa que acompaña este artículo.

\section{Referencias}

Alarcón-Chaires, P. (2001). Los indígenas cucapá y la conservación de la naturaleza. El infortunio de vivir en un área natural protegida en México. Ecología Política, 117-129. Recuperado de https://dialnet.unirioja.es/descarga/articulo/153464.pdf

Boege, E. (2008). El patrimonio biocultural de los pueblos indígenas de México. Hacia la conservación in situ de la biodiversidad y agrodiversidad en los territorios indígenas. México: Instituto Nacional de Antropología e Historia y CDI.

Bravo-Espinosa, Y. (2018). Protección del medio ambiente y derechos de los pescadores cucapá. Un análisis dicotómico o un despojo anunciado por el Estado neoliberal. En Aleida Hernández Cervantes y Mylai Burgos Matamoros (coords.), La disputa por el derecho: la globalización hegemónica vs. la defensa de los pueblos y grupos sociales (pp. 423-454). Ciudad de México: Universidad Nacional Autónoma de México (UNAM), Bonilla Artigas Editores.

Broda, J. (1991). Cosmovisión y observación de la naturaleza: el ejemplo del culto de los cerros. En Johanna Broda, Stanislav I. Waniszewski y Lucrecia Mauponé (eds.), Arqueoastronomía y etnoastronomía en Mesoamérica (pp. 461-500). Ciudad de México: IIH, UNAM.

Caballero, J. (1985). Exploración de recursos genéticos potenciales. En H. Palomino y E. Pimienta (eds.), Memorias del Seminario sobre Investigación Genética Básica en el Conocimiento y Evaluación de los Recursos Genéticos (pp. 28-40). Ciudad de México: Jardín Botánico de la UNAM y SOMEFI. 
Castro, G. (2006). El agua y los ríos amenazados en México. Los retos para el Movimiento Social Anti-Represas. Revista del Observatorio Social de América Latina, 7(21), 159-112. Recuperado de http://biblioteca.clacso.edu.ar/ar/ libros/osal/osal21/Soto.pdf

Centro de Estudios para el Desarrollo Rural Sustentable y la Soberanía Alimentaria (CEDRSSA). (2015). La población indígena en el México rural: situación actual y perspectivas. Recuperado de http://www.cedrssa.gob.mx/post_ la_poblacinin_-n-indn-gena-n-_en_el_mn-xico_-n-rural-_situacinin-n-_actual_y_perspectivas.htm /

Chávez-Galindo, R. (2010). El movimiento mexicano de afectados por las presas. La Jornada del Campo, 31. Recuperado de https://www.jornada.com. $\mathrm{mx} / 2010 / 04 / 17 /$ presas.html

Comisión Económica para América Latina y El Caribe. (2018). Acuerdo Regional sobre el Acceso a la Información, la Participación Pública y el Acceso a la Justicia en Asuntos Ambientales en América Latina y el Caribe. Escazú (Costa Rica): Publicaciones de la CEPAL. Recuperado de https: / /www.cepal.org/es/ acuerdodeescazu

Comisión Interamericana de Derechos Humanos (CIDH). (2010). Derechos de los pueblos indígenas y tribales sobre sus tierras ancestrales y recursos naturales. Normas y jurisprudencia del Sistema Interamericano de Derechos Humanos Washington, DC: Organización de los Estados Americanos (publicación con clave OEA/Ser.L/V/II). Recuperado de https://www.oas.org/es/cidh/indigenas/docs/pdf/Tierras-Ancestrales.ESP.pdf

Comisión Nacional del Agua (CONAGUA). (1998). Cuencas Hidrológicas. Escala 1:250000. México. Shapefile. Formato vectorial compuesto por 4 archivos (shp, shx, dbf, prj). Recuperado de http://geoportal.conabio.gob.mx/metadatos/doc/html/cue250kgw.html/

Comisión Nacional del Agua (CONAGUA). (2005). Estadísticas del agua en México, 2005. Recuperado de https://www.gob.mx/cms/uploads/attachment/ file/259369/_2005_EAM2005.pdf

Comisión Nacional del Agua (CONAGUA). (2007). Estadísticas del agua en México, 2007. Recuperado de http://www.conamexphi.com/wp-content/ uploads/2017/09/2007EAM2007.pdf

Comisión Nacional del Agua (CONAGUA). (2008). Estadísticas del agua en México, 2008. Recuperado de https://www.gob.mx/cms/uploads/attachment/ file/259370/_2008_EAM2008.pdf

Comisión Nacional del Agua (CONAGUA). (2011). Estadísticas del agua en México, 2011. Recuperado de https://www.gob.mx/cms/uploads/attachment/ file/259373/_2011_EAM2011.pdf

Comisión Nacional del Agua (CONAGUA). (2015). Mapa que muestra los municipios con mayor riesgo a la sequía. Datos Abiertos. México. Shapefile. Formato vectorial compuesto por 6 archivos (shp, shx, sbx, sbn, dbf, prj). Recuperado de https://datos.gob.mx/busca/dataset/municipios-en-riesgo-por-sequias-de-conagua/resource/980714bc-79e2-413a-86ff-40e7094b1212 
Comisión Nacional del Agua (CONAGUA). (2018). Estadísticas del agua en México, 2018. Recuperado de https://www.gob.mx/conagua/acciones-y-programas/publicaciones-estadisticas-y-geograficas-60692/

Comisión Nacional para el Conocimiento y Uso de la Biodiversidad (CONABIO). (1999). Localidades con población hablante de lengua indígena mayor al 75\%, 1995. Obtenido de Conteo de población y vivienda. Resultados definitivos. Instituto Nacional de Estadística Geografía e Informática (INEGI). (1995). México. Shapefile. Formato vectorial compuesto por 4 archivos (shp, shx, dbf, prj). Recuperado de http://geoportal.conabio.gob.mx/metadatos/doc/ html/cue250kgw.html/

Consejo Económico y Social de las Naciones Unidas (NU). (23 de diciembre de 2003). Informe del Relator especial sobre la situación de los derechos humanos y las libertades fundamentales de los indígenas, Sr. Rodolfo Stavenhagen. Adición. Misión a México. Comisión de Derechos Humanos. $60^{\circ}$ periodo de sesiones. (Publicación con clave E/CN.4/2004/80/Add.2). Recuperado de https: / / acnur.org / fileadmin/Documentos/BDL/2006/4357.pdf?view=1

Cotler, H., Garrido, A., Mondragón, R., y Díaz, A. (2007). Delimitación de las Cuencas hidrográficas de México a escala 1:250 000. México: INEGI, INE y CONAGUA.

Diario Oficial de la Federación (DOF). (1 de diciembre de 1992). Ley de Aguas Nacionales. Cámara de Diputados del H. Congreso de la Unión. Secretaría General. Secretaría de Servicios Parlamentarios. Última reforma: 6 de enero de 2020. Recuperado de http://www.diputados.gob.mx/LeyesBiblio/ pdf/16_060120.pdf

Diario Oficial de la Federación (DOF). (11 de agosto de 2014a). Ley de Energía Geotérmica. Cámara de Diputados del H. Congreso de la Unión. Secretaría General. Secretaría de Servicios Parlamentarios. Nueva ley. Recuperado de http://www.diputados.gob.mx/LeyesBiblio/pdf/LEG_110814.pdf

Diario Oficial de la Federación (DOF). (11 de agosto de 2014b). Ley de Hidrocarburos. Cámara de Diputados del H. Congreso de la Unión. Secretaría General. Secretaría de Servicios Parlamentarios. Última reforma: 15 de noviembre de 2016. Recuperado de http://www.diputados.gob.mx/LeyesBiblio/pdf/LHidro_151116.pdf

Diario Oficial de la Federación (DOF). (26 de junio de 1992). Ley Minera. Cámara de Diputados del H. Congreso de la Unión. Secretaría General. Secretaría de Servicios Parlamentarios. Última reforma: 11 de agosto de 2014. Recuperado de http://www.diputados.gob.mx/LeyesBiblio/pdf/151_110814.pdf

Diario Oficial de la Federación (DOF). (6 de marzo de 2020). Constitución Política de los Estados Unidos Mexicanos. [5 de febrero de 1917]. Texto vigente. Última reforma: 6 de marzo de 2020, Cámara de Diputados del H. Congreso de la Unión. Secretaría General. Secretaría de Servicios Parlamentarios. Recuperado de http://www.diputados.gob.mx/LeyesBiblio/pdf/1_060320.pdf

Diario Oficial de la Federación (DOF). (7 de junio de 2013). Decreto por el que se expide la Ley Federal de Responsabilidad Ambiental y se reforman, adicionan 
y derogan diversas disposiciones de la Ley General del Equilibrio Ecológico y la Protección al Ambiente, de la Ley General de Vida Silvestre de la Ley General para la Prevención y Gestión Integral de los Residuos, de la Ley General de Desarrollo Forestal Sustentable, de la Ley de Aguas Nacionales, del Código Penal Federal, de la Ley de Navegación y Comercio Marítimos y de la Ley General de Bienes Nacionales. Secretaría de Gobernación. Recuperado de http: / / www.dof.gob.mx/nota_detalle.php?codigo=5301688\&fecha=07/06/2013

Félix-Báez, J. (1992). Las voces del agua. El simbolismo de las sirenas y las mitologías americanas. Xalapa: Universidad Veracruzana.

Forero-Mantilla, F. (2010). Conectividad: alcances del derecho a la propiedad aborigen y tribal en la jurisprudencia de la Corte Interamericana de Derechos Humanos. International Law: Revista Colombiana de Derecho Internacional, 8(16). Recuperado de https://revistas.javeriana.edu.co/index.php/internationallaw/article/view/13837

Gálvez, X. (2004). Los otros desplazados. En E. Zebadúa (coord.). Desplazados internos en México. Ciudad de México: Cámara de Diputados. Recuperado de https: //archivos.juridicas.unam.mx/www/bjv/libros/7/3486/26.pdf

Giménez, G. (1994). Apuntes para una teoría de la región y de la identidad regional. Estudios sobre las Culturas Contemporáneas, 6(18), 165-173. Recuperado de http: / / www.redalyc.org/articulo.oa?id=31661809

González-Pagés, A. (2006). Leyendas del agua en México. Jiutepec: Instituto Mexicano de Tecnología del Agua (IMTA). Recuperado de https://www.imta. gob. mx/biblioteca/download/?key=209

Hernández-Garciadiego, R. (2005). El secreto tecnológico del complejo hidroagroecológico más antiguo de Mesoamérica: El complejo de Purrón. Alternativas y Procesos de Participación Social, A. C. Recuperado de http://www. alternativas.org.mx/El\%20Complejo\%20de\%20Purron.pdf

Instituto Nacional de Estadística y Geografía (INEGI). (2010) Censo general de población y vivienda. Recuperado de http://www3.inegi.org. mx/rnm/index. php/catalog/71/related_materials?idPro

Instituto Nacional de los Pueblos Indígenas. (2020). Bases de datos por municipio 2010. Indicadores de la población indígena. Cédulas de información municipal. Archivo de Excel. Recuperado de http://www.inpi.gob.mx/cedulas/ index.html

Liffman, P. (2017). El agua de nuestros hermanos mayores. La cosmopolítica antiminera de los wixaritari y sus aliados. En G. Olivier y J. Neurath (eds.), Mostrar y ocultar en el arte en los rituales: perspectivas comparativas (pp. 563-588). Ciudad de México: UNAM, Instituto de Investigaciones Estéticas e Instituto de Investigaciones Históricas. Recuperado de https://scholar.google.com/scholar?oi=bibs\&cluster=12379575764587342447\&btnl=1\&hl=es

López-Austin, A., y López-Luján, L. (1996). El pasado indígena. Ciudad de México: Fondo de Cultura Económica.

López-Bárcenas, F. (2018). El acueducto Independencia: entre los derechos y la política. En Aleida Hernández Cervantes y Mylai Burgos Matamoros (coords.), 
La disputa por el derecho: la globalización hegemónica vs. la defensa de los pueblos y grupos sociales (pp. 489-526). Ciudad de México: UNAM, Bonilla Artigas Editores.

López-Ledesma, M. E. (2018). La dimensión cultural en la restitución de los territorios ancestrales y el criterio de la Corte Interamericana de derechos humanos. Revista “Cuadernos Manuel Giménez Abad", (16), 108-130. Recuperado de https://dialnet.unirioja.es/descarga/articulo/6718257.pdf

Martínez-Ruiz, J. L., y Murillo-Licea, D. (coords.). (2016). Agua en la cosmovisión de los pueblos indígenas en México. Secretaría del Medio Ambiente y Recursos Naturales, CONAGUA, IMTA. Recuperado de https://www.imta.gob. $\mathrm{mx} /$ biblioteca/download/?key=9943113

México Desconocido. (2010). Las presas, un reto cumplido. Recuperado de https://www.mexicodesconocido.com.mx/las-presas-un-reto-cumplido.html

Murillo-Licea, D. (2019). Territorialidades indígenas y agua, más allá de las cuencas hidrográficas. Agua y Territorio, 14, 33-44. doi: https://doi.org/10.17561/ at.14.4509

Navarrete, F. (2004). Las relaciones interétnicas en México. Recuperado de http: / / www.librosoa.unam.mx/handle/123456789/321

Oficina del Alto Comisionado para los Derechos Humanos (OACNUDH). (2 de agosto de 2017). Informe del Relator Especial sobre el derecho humano al agua potable y el saneamiento acerca de su misión a México. Asamblea General de las Naciones Unidas, XXXVI36 periodo de sesiones del 11 a 29 de septiembre de 2017. (Publicación con clave A/HRC/36/45/Add.2), 11 a 29 de septiembre de 2017. Recuperado de https://undocs.org/es/A/HRC/36/45/Add.2

Oficina del Alto Comisionado para los Derechos Humanos (OACNUDH). (28 de junio de 2018). Informe de la Relatora Especial sobre los derechos de los pueblos indígenas sobre su visita a México. Asamblea General de las Naciones Unidas. Consejo de Derechos Humanos. XXXIX39॰ periodo de sesiones del 10 al 28 de septiembre de 2018. (Publicación con clave A/HRC/39/17/Add.2). Recuperado de https://www.ohchr.org/EN/Issues/IPeoples/SRIndigenousPeoples/Pages/CountryReports.aspx 